\title{
PENINGKATAN PRODUKTIVITAS PRODUKSI KAIN BATIK MENGGUNAKAN METODE LEAN DAN KAIZEN DI UMKM SANGGAR BATIK JUMPUTAN MAHARANI
}

\author{
Aldi Yoga Pradana, Mochammad Danang Dwi Setyo Perdana, Dessy Deria Ginting \\ Jurusan Teknik Industri, Fakultas Sains dan Teknologi, Yogyakarta \\ aldiyogapradana98@gmail.com, danangperdana00@gmail.com, ciciginting989@gmail.com
}

\begin{abstract}
Productivity is one of the determinants of production in an industry ranging from UMKM to companies. UMKM Sanggar Batik Jumputan Maharani, which produces batik jumput uses traditional techniques to maintain quality takes 149 hours. The process of producing one batik cloth usually takes one week. Therefore an increase in productivity is needed, one of the methods that is appropriate for this problem is the Lean and Kaizen method. The Lean method that focuses on identifying waste is then followed by the Kaizen method for continuous improvement. First, initial identification is carried out on the production map to see waste. Second, the amount of batik production jumps every month to find out how much production each month. Third, data work in process for making one batik cloth. After obtaining the results of the 3 stages then processing using the Lean and Kaizen methods. The results of processing these two methods can increase the amount of production every week and reduce the workload on employees who previously needed a long time to complete one cloth.
\end{abstract}

Keywords: productivity, Lean, Kaizen

\begin{abstract}
Abstrak
Produktivitas merupakan salah satu penentu hasil produksi dalam suatu industry mulai dari UMKM hingga perusahaan. Pada UMKM Sanggar Batik Jumputan Maharani yang memproduksi batik jumput menggunakan teknik tradisional untuk menjaga kualitas membutuhkan waktu 149 jam. Proses memproduksi satu kain batik biasanya membutuhkan waktu satu minggu. Oleh karena itu diperlukan peningkatan produktivitas, salah satu metode yang pas untuk masalah ini adalah metode Lean dan Kaizen. Metode Lean yang focus pada identifikasi waste kemudian dilanjutkan metode Kaizen untuk dilakukan peningkatan yang berkelanjutan. Pertama identifikasi awal dilakukan pada peta produksi untuk melihat terdapat waste. Kedua, jumlah produksi batik jumputan setiap bulan untuk mengetahui seberapa banyak jumlah produksi setiap bulan. Ketiga, data work in process pada pembuatan satu kain batik. Setelah didapat hasil 3 tahap tersebut kemudian dilakukan pengolahan menggunakan metode Lean dan Kaizen. Hasil dari pengolahan dua metode ini dapat meningkatkan jumlah produksi setiap minggu dan pengurangan beban kerja pada karyawan yang sebelumya membutuhkan waktu yang lama untuk menyelesaikan satu kain.
\end{abstract}

Kata kunci: produktivitas, Lean, Kaizen

\section{PENDAHULUAN}

Peningkatan UMKM di Indonesia, terutama di Yogyakarta mengalami pertumbuhan yang pesat beberapa tahun ini. Batik merupakan salah satu produk unggulan yang saat ini sedang diminati masyarakat domestic dan mancanegara.Batik merupakan salah satu kerajinan tangan yang popular di Indonesia maupun di luar negeri. Keindahan batik menjadi khas karena pembuatan yang dilakukan secara tradisional memberikan hasil berbeda daripada batik mengunakan alat. Dala pembuatan batik membutuhkan waktu dan tempat yang luas dan berdekatan untuk meminimalkan waktu pembuatan agar tidak membutuhkan waktu yang terlalu lama yaitu 149 jam.

Semakin efisien sistem produksi perusahaan tersebut, maka semakin sedikit timbulnya waste dalam aktivitas produksi mereka. Menurut Hines \& Taylor (2000), salah satu paremeter produktivitas yang diinginkan yaitu untuk meminimasi waste yang dihasilkan dalam setiap proses pengerjaan. Waste yang 
banyak terjadi tentunya akan menghambat usaha dari perindutsrian tersebut. Oleh karena itu, sudah seharusnya waste dapat dikurangi dalam sebuah proses produksi.

Perkembangan teknologi yang pesat saat menunjang keberhasilan pembatan batik dengan waktu yang singkat. Namun, produk batik Sanggar Batik Jumputan Maharani tidak menggunakannya. Pembuatan masih bertahan dengan metode tradisional untuk menjaga keaslian dan ciri khas batik tradisional namun berkesan modern dengan batik yang sedang trend saat ini.

Untuk menerapkan perbaikan secara kontinu tersebut maka dibutuhkan suatu pendekatan yang dapat digunakan dengan benar agar perbaikan yang terus menerus (continuous improvement) tersebut dapat terwujud. Menurut Gaspersz (2006), konsep lean manufacturing merupakan suatu upaya strategi perbaikan secara kontinu dalam proses produksi untuk mengidentifikasi jenis-jenis dan faktor penyebab terjadinya waste agar aliran nilai (value stream) dapat berjalan lancar sehingga waktu produksi lebih efisien. Pendekatan lean manufacturing merupakan pendekatan yang relatif sederhana dan terstruktur dengan baik agar mudah dipahami demi melakukan proses efisiensi yang sesuai dengan kemampuan dan sumber daya yang ada di perusahaan. Lean manufacturing didefinisikan sebagai pereduksi dari waste dalam segala bentuk atau kondisi dengan memaksimalkan aktivitas yang bernilai tambah (value added). Menurut Womack (1990), konsep lean berarti suatu usaha oleh seluruh elemen perusahaan untuk bersama-sama mengeliminasi waste dan merupakan salah satu tools untuk mencapai daya saing perusahaan seoptimal mungkin. Pendekatan lean manufacturing memahami keseluruhan proses bisnis yang meliputi proses produksi, aliran material, dan aliran informasi. Salah satu tool yang sangat bermanfaat dan juga sederhana yang sering digunakan untuk memetakan keseluruhan proses bisnis tadi adalah Value Stream Mapping (VSM).

Keseluruhan informasi tersebut ditampilkan secara unik dalam current state map, seperti aliran informasi suatu proses produksi, cycle time, jumlah persediaan, machine uptime, dan jumlah pekerja. Dengan pendekatan lean manufacturing ini, aliran informasi dan material dari perusahaan digambarkan dengan value stream mapping untuk mengetahui waste yang ada. Tujuan utama dari Value Stream Mapping (VSM) adalah untuk memahami dan mendokumentasikan semua proses yang ada pada saat ini dengan semua persoalan didalamnya untuk kemudian menghasilkan future state map yang mendukung terjadinya perbaikan dalam proses produksi tersebut. Selain melakukan perbaikan secara berkelanjutan dengan metode Lean, dapat dilanjutkan menggunakan metode Kaizen sebagai tindakan lanjutan sebagai pendamping peningkatan produktivitas. Kaizen adalah suatu istilah dalam bahasa Jepang yang dapat diartikan sebagai perbaikan secara terus-menerus (continuous improvement) (Gaspers, 2003).Kaizen pada setiap perusahaan, baik perusahaan manufaktur atau bukan, harus dimulai dengan tiga kegiatan ini : standardisasi, 5R dan penghapusan pemborosan.

Menurut Gaspersz (2007), lean manufacturing merupakan suatu sistem produksi yang menggunakan energi dan pemborosan yang sangat sedikit untuk memenuhi apa yang menjadi keinginan konsumen dengan tepat. Tujuan dari lean manufacturing adalah mengeliminasi pemborosan (non value adding activity) dari suatu proses sehingga aktivitas-aktivitas sepanjang value stream mampu menghasilakan value adding.

Dalam aplikasi lean, pemborosan atau waste harus di eliminasi. Pemborosan merupakan aktivitas yang tidak memiliki nilai tambah. Oleh karena itu, pemborosan harus dieliminasi karena dapat menyebabkan proses produksi menjadi lebih efisien. Berdasarkan Kaufman group (1999) dalam Gazpers (2011) terdapat sepuluh pemborosan yang terbagi menjadi 4 kategori antara lain sebagai berikut. 1. Orang (People) Pemborosan ini merupakan pemborosan yang diakibatkan oleh manusia. Terdapat 3 jenis pemborosan pada kategori ini antara lain. a. Inappropriate Processing b. Excessive Motion c. Waiting 2. Kuantitas (Quantity) Pemborosan ini merupakan pemborosan yang terjadi 
disebabkan oleh jumlah produk yang berada pada sepanjang aliran proses produksi. Pemborosan ini terbagi menjadi 3 macam antara lain. a. Unnecessary Inventory b. Unnecessary Moving Things / Transportation c. Overproduction. Kualitas (Unconforming Quality) / Defect Pemborosan ini terjadi akibat adanya kesalahan pada proses pengerjaan sepanjang proses produksi yang berdampak pada kualitas produk akhir dimana hal ini sangat menentukan kepuasan konsumen dalam penggunaan produk. 4. Informasi (Information) Pemborosan ini terjadi akibat adanya aliran informasi yang salah pada setiap tahapan proses. Pemborosan ini terbagi menjadi 3 jenis pemborosan antara lain. a. Ineffective Planning b. Ineffective Scheduling c. Discrepancy Execution Pemborosan atau waste, dalam bahasa Jepang disebut muda, merupakan segala sesuatu tindakan yang dilakukan tanpa menghasilkan nilai. Taiichi Ohno, seorang eksekutif Toyota, merupakan orang pertama yang mencetuskan tujuh macam pemborosan. Kemudian Linker menambahkan satu jenis pemborosan pada tujuh macam pemborosan tersebut (Daonil, 2012). Lean manufacturing adalah suatu pendekatan sistematis untuk mengidentifikasi dan mengeliminasi pemborosan berupa aktivitas yang tidak memberi nilai lebih (non-value added activities) melalui perbaikan secara terus menerus dengan mengizinkan aliran produk dengan sistem tarik (pull system) dari sudut pelanggan dengan tujuan kesempurnaan kepuasaan pelanggan (Fontana, 2011).

Beberapa penelitian terkait dengan penerapan konsep lean manufacturing antara lain: Daonil (2012) menggunakan metode Value Steam Mapping untuk menghilangkan pemborosan di perusahaan dying dan printing; Sandroto (2007) yang menggunakan metode Value Stream Mapping pada industri susu balita; Muzakki (2012) menerapkan lean manufacturing untuk mengeliminasi waste pada lini machining cast wheel; Pertiwi (2012) menggunakan konsep lean hospital untuk perbaikan sistem rack addressing dan order picking di sebuah rumah sakit; Chaeron (2014) mengimplementasikan konsep lean thinking di PT Adi Satria Abadi (divisi penyamakan kulit). Berbeda dengan penelitian-penelitian sebelumnya, penelitian dalam paper ini dilakukan di PT Adi Satria Abadi (divisi sarung tangan kulit) dan menganalisis implementasi lean manufacturing pada industri sarung tangan kulit.

Heizer dan Render (2005:307) menyatakan bahwa Kaizen termasuk dalam tujuh konsep program Total Quality Management (TQM) yang efektif yang merupakan penyempurnaan dari 14 poin Edward Deming. Tujuh konsep program TQM yang efektif tersebut antara lain: Perbaikan berkesinambungan (Kaizen), Six Sigma, Pemberdayaan Pekerja, Benchmarking, Just In Time (JIT), Konsep Taguchi, dan Seven Tools Perangkat TQM.

Cane (1998) dalam Paramita (2012) menjelaskan dalam bahasa Jepang, kaizen berarti perbaikan yang berkesinambungan (continuous improvement). Ciri kunci manajemen kaizen antara lain lebih memperhatikan proses dan bukan hasil, manajemen fungsional silang dan menggunakan lingkaran kualitas dan peralatan lain untuk mendukung peningkatan yang terus menerus.

Ferdiansyah (2011) menyatakan bahwa tujuan kaizen antara lain yaitu meningkatkan QCD (Quality, Cost, Delivery) yang dimana sasaran utama dari hal-hal tersebut ialah meningkatkan kepuasan pelanggan dan meningkatkan kesetiaan konsumen.

Paramitha (2012) menyatakan bahwa kaizen memiliki beberapa konsep yang dapat digunakan perusahaan dalam melakukan perbaikan, konsep tersebut yaitu: Konsep 3M (Muda, Mura, dan Muri), Konsep gerakan 5S (Seiri, Seiton, Seiso, Seiketsu dan Shitsuke), konsep PDCA (Plan, Do, Check dan Action), dan Konsep $5 \mathrm{~W}+1 \mathrm{H}$.

a. Konsep 3M (Muda, Mura, Muri)

Kato dan Art Smalley (2011:34) menjelaskan Muda adalah segala kegiatan yang bernilai mubasir atau aktivitas pemborosan yang tidak menambahkan nilai pada produk atau jasa. Kato dan Art Smalley (2011:34) menjelaskan bahwa Mura dapat diartikan sebagai suatu proses yang tidak merata atau tidak teratur dalam kegiatan proses produksi. Kato dan Art Smalley (2011:34) menyatakan bahwa Muri 
dapat diartikan sebagai pembebanan yang berlebihan atau melampaui batas kemampuan para pekerja dalam melakukan pekerjaannya.

b. Konsep Gerakan 5S (Seiri, Seiton, Seiso, Seiketsu dan Shitsuke)

Ekoanindiyo (2013) menjelaskan bahwa Seiri (memisah-misahkan). Seiri berarti memisah-misahkan berkas-berkas atau barang-barang dalam beberapa kategori. Kategori tersebut terdiri dari barang-barang yang sering kita gunakan sehingga perlu diletakkan di tempat yang lebih dekat dari tempat kerja kita, barang- barang yang tidak sering kita gunakan sehingga dapat diletakkan di tempat yang jauh dari tempat kerja kita, dan barang-barang yang tidak pernah digunakan dapat disingkirkan atau dihapus.

Menurut Gaspersz (2006), konsep lean manufacturing merupakan suatu upaya strategi perbaikan secara kontinu dalam proses produksi untuk mengidentifikasi jenisjenis dan faktor penyebab terjadinya waste agar aliran nilai (value stream) dapat berjalan lancar sehingga waktu produksi lebih efisien. Pendekatan lean manufacturing merupakan pendekatan yang relatif sederhana dan terstruktur dengan baik agar mudah dipahami demi melakukan proses efisiensi yang sesuai dengan kemampuan dan sumber daya yang ada di perusahaan. Lean manufacturing didefinisikan sebagai pereduksi dari waste dalam segala bentuk atau kondisi dengan memaksimalkan aktivitas yang bernilai tambah (value added).

Kaizen adalah suatu istilah dalam bahasa Jepang yang dapat diartikan sebagai perbaikan secara terus - menerus (continuous improvement) (Gaspers, 2003).Kaizen pada setiap perusahaan, baik perusahaan manufaktur atau bukan, harus dimulai dengan tiga kegiatan ini : standardisasi, $5 \mathrm{R}$ dan penghapusan pemborosan.

\section{METODE PENELITIAN}

Berikut ini adalah metode penelitian yang digunakan:

1. Studi Lapangan (Field Research)

Metode ini digunakan dalam pengumpulan data yang dilakukan secara langsung dengan melakukan survei pendahuluan untuk menggali informasi yang dibutuhkan yang berkaitan di UKM Sanggar Batik Jumputan Maharani.

2. Studi Literatur (Library Research)

Studi literatur merupakan suatu metode yang digunakan dalam mendapatkan data dengan jalan mempelajari literatur serta membaca sumber data informasi lainnya yang berhubungan dengan pembahasan. Teori-teori yang dipelajari pada penelitian ini adalah mengenai konsep Lean dan Kaizen.

3. Identifikasi Masalah Identifikasi masalah merupakan tahap awal dalam mengetahui dan memahami permasalahan agar dapat diberikan solusi.

4. Perumusan Masalah

Setelah mengidentifikasi permasalahan, dilanjutkan dengan merumuskan masalah sesuai dengan kenyataan di lapangan, yaitu bagaimana penanganan pemborosan yang terjadi di UKM Sanggar Batik Jumputan Maharani

5. Penentuan Tujuan Penelitian

Tujuan penelitian perlu ditetapkan agar penulisan skripsi dapat dilakukan secara sistematis dan tidak menyimpang dari permasalahan yang dibahas, Tujuan penelitian ditentukan berdasarkan perumusan masalah yang telah dijabarkan

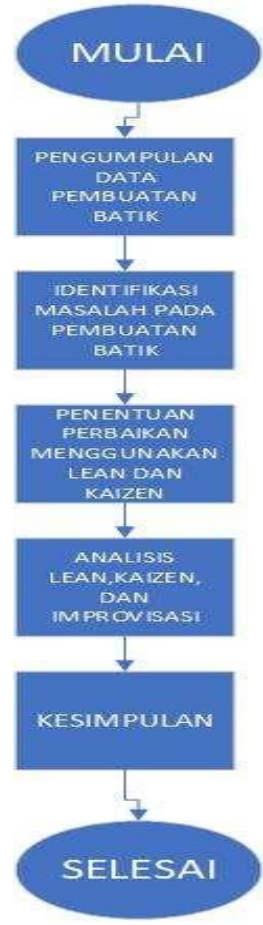

Gambar 1. Diagram Alir Penelitian (Sumber: Olah Data, 2019) 


\section{HASIL DAN PEMBAHASAN}

Hasil

Setelah melakukan studi lapangan didapatkan data pada tabel-tabel sebagai berikut:

Tabel 1. Data Jumlah Produksi

\begin{tabular}{|c|l|c|}
\hline No & \multicolumn{1}{|c|}{ Bulan } & $\begin{array}{c}\text { Jumlah Produksi } \\
\text { (lembar) }\end{array}$ \\
\hline 1 & Januari & 80 \\
\hline 2 & Februari & 45 \\
\hline 3 & Maret & 40 \\
\hline 4 & April & 65 \\
\hline 5 & Mei & 72 \\
\hline 6 & Juni & 56 \\
\hline 7 & Juli & 83 \\
\hline 8 & Agustus & 103 \\
\hline 9 & September & 68 \\
\hline 10 & Oktober & 77 \\
\hline 11 & November & 92 \\
\hline 12 & Desember & 120 \\
\hline \multicolumn{2}{|c|}{ Total } & 901 \\
\hline
\end{tabular}

(Sumber: Surani, 2018)

Tabel 2. Work in Process

\begin{tabular}{|l|l|l|l|}
\hline No. & \multicolumn{1}{|c|}{ Proses } & $\begin{array}{c}\text { Waktu } \\
\text { Siklus } \\
\text { (jam) }\end{array}$ & $\begin{array}{c}\text { Work in } \\
\text { Process } \\
\text { (Unit) }\end{array}$ \\
\hline 1 & $\begin{array}{l}\text { Pemilihan Bahan } \\
\text { Baku }\end{array}$ & 1 & 3 \\
\hline 2 & $\begin{array}{l}\text { Pemotongan } \\
\text { Bahan Baku }\end{array}$ & 1 & 3 \\
\hline 3 & Pembuatan Pola & 48 & 6 \\
\hline 4 & Penjumputan & 24 & 18 \\
\hline 5 & Pewarnaan & 1 & 3 \\
\hline 6 & $\begin{array}{l}\text { Pengerigan di } \\
\text { bawah Sinar } \\
\text { Matahari }\end{array}$ & 48 & 3 \\
\hline 7 & $\begin{array}{l}\text { Pengeringan di } \\
\text { dalam Ruangan }\end{array}$ & 24 & 3 \\
\hline 8 & $\begin{array}{l}\text { Pelepasan } \\
\text { Jumputan }\end{array}$ & 1 & 18 \\
\hline 9 & Setrika & 1 & 3 \\
\hline & Total & 149 & 60 \\
\hline
\end{tabular}

(Sumber: Surani, 2018)

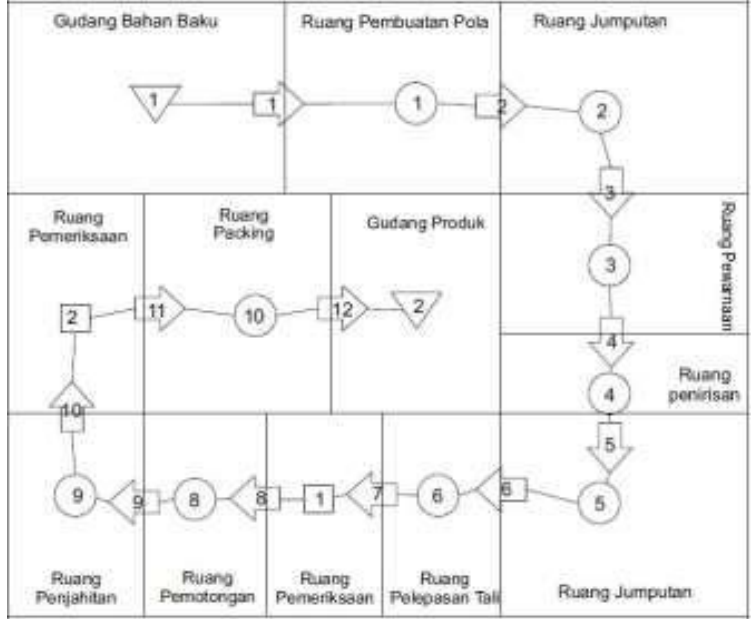

Gambar 2. Peta Alir Produksi

(Sumber: Surani, 2019)

\section{Pembahasan}

Setelah mendapatkan 3 data tersebut didapat adanya waste pada proses produksi yang terlalu banyak terjadi perpindahan yang menambah waktu produksi namun bisa dihilangkan untuk mempersingkatnya. Berikut ini peta alir produksi yang telah dilakukan peminimalan kegiatan produksi:

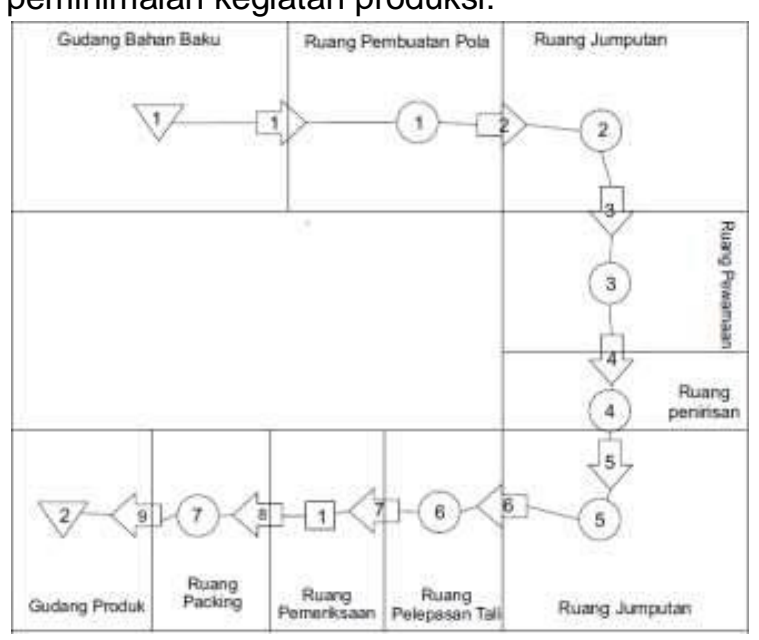

Gambar 3. Usulan Peta Produksi

(Sumber: Olah Data, 2019)

Pada usulan peta produksi dilakukan pemadatan proses pada bagian ruang pemeriksaan yang digabungkan yang sebelumnya harus melewati ruang pelepasan tali, pemotongan, penjahitan, dan pemeriksaan. Pemadatan proses produksi pada 4 bagian tersebut bisa dilakukan pada satu proses produksi yaitu pada ruang pemeriksaan. 


\section{KESIMPULAN}

Penelitian ini mendapatkan data peta alir produksi yang terlalu banyak kegiatan yang menimbulkan waste karena 4 proses tersebut dapat dilakukna pada satu proses produksi. Dengan adanya usulan tersebut diharapkan dapat mengurangi waktu produksi karena telah dilakukan pemadatan, sehingga hasil produksi dalam setiap bulannya terjadi peningkatan yang berkelanjutan.

\section{DAFTAR PUSTAKA}

Daonil. 2012.Tesis : Implementasi Lean Manufacturing Untuk Eliminasi Waste Pada Lini Produksi Machining Cast Wheel Dengan Menggunakan Metode Wam Dan Valsat, Tahun 2012, Depok:Fakultas Teknik Program Studi Teknik Industri Universitas Indonesia.

Ferdiansyah H. 2011. Usulan Rencana Perbaikan Kualitas Produk Penyangga Duduk Jok Sepeda Motor Dengan Pendekatan Metode Kaizen $(5 \mathrm{~W}+1 \mathrm{H}) \mathrm{Di}$ PT EKAPRASARANA. Jurnal Manajemen, hal 1-10.

Fontana, Avanti , Gaspers, V., 2011. Lean Six Sigma For Manufacturing and Service Industries. Bogor : Vinchristo Publication.

Gaspersz, V.; dan Fontana, A. 2011. Lean Six Sigma for Manufacturing and Engineering. Proceedings of International Conference on Industrial Engineering and Operations Management 2011. Kuala Lumpur.

Gasperz, V., \& Fontana, A. 2011. Lean Six Sigma for Manufacturing and Service Industries. Bogor: Vinchristo Publication,

Heizer J, Barry R. 2005. Manajemen Operasi. Jakarta: Salemba Empat.

Muzakki, Misbahul. 2012. Skripsi: Perancangan Sistem Produksi Untuk Mencapai Kondisi Lean Manufacturing Menggunakan Value Stream Mapping pada Sektor Industri Susu Balita Tahun 2012, Depok: Fakultas Teknik Universitas Indonesia

Pertiwi, Kusuma. 2012. Skripsi : Lean Hospital Sebagai Usulan Perbaikan Sistem Rack Addressing dan Order Picking Gudang Logistik Perbekalan Kesehatan Rumah Sakit Islam Jakarta Cempaka Tahun
2012, Depok: Fakultas Kesehatan Masyarakat Universitas Indonesia.

Zaqi Ari A Ffaritsy, Suseno. 2015. Peningkatan

Produktivitas Perusahaan Dengan

Menggunakan Metode Six Sigma, Lean dan Kaizen. Yogyakarta. 